\title{
The effect of zinc oxide nanoparticle morphology on activity in crosslinking of carboxylated nitrile elastomer
}

\author{
M. Przybyszewska*, M. Zaborski \\ Institute of Polymer and Dye Technology, Technical University of Lodz, Stefanowskiego 12/16, Lodz 90-924, Poland
}

Received 27 April 2009; accepted in revised form 9 June 2009

\begin{abstract}
The aim of this work was to study the activity of several nanosized zinc oxides in the crosslinking of carboxylated nitrile elastomer (XNBR). In this article, we discuss the effect of zinc oxide nanoparticles with respect to their specific surface area, particle size and morphology (spheres, whiskers, and snowflakes) on the crosslinking density and mechanical properties of vulcanisates.

The morphology of nanoparticles considerably influences the activity of zinc oxide towards carboxylated nitrile rubber. As a crosslinking agent, zinc oxide with snowflake particles seems to be the most active. The application of nanosized zinc oxide allows the amount of $\mathrm{ZnO}$ to be reduced by almost $40 \%$, as compared to vulcanisates containing microsized particles. Moreover, vulcanisates crosslinked with zinc oxide nanoparticles exhibit thermoplastic properties that enable this material to be recycled, which is very important from an ecological point of view.
\end{abstract}

Keywords: nanocomposites, rubber, mechanical properties, zinc oxide, carboxylated nitrile elastomer

\section{Introduction}

Carboxylated nitrile rubber (XNBR) can be crosslinked by sulphur with accelerators; however, the most relevant method is the application of bivalent metal oxides, especially zinc oxide $(\mathrm{ZnO})[1$, 2]. The crosslinking of elastomer occurs via the reaction of its carboxylic groups with zinc oxide, resulting in the formation of carboxylic salts, considered to be ionic crosslinks. In contrast to the covalent crosslinks formed during conventional vulcanisation with sulphur/accelerator systems or peroxides, ionic crosslinks are multifunctional and labile [3]. Carboxylic salts group together, forming clusters or multiplets [4]. According to Ibarra and Alzorriz [2], multiplets consist of six to eight dipole ions associated to form larger multiplets, which disperse in the elastomer matrix without forming a separate phase. These multiplets have a considerable impact on the glass transition temperature of the elastomer and its sensitivity to water. Clusters are considered as ionic aggregates, in separate ionpair-rich regions, immersed in an elastomer matrix [1]. The presence of ionic clusters is responsible for the improved physical properties of ionic elastomers, even without filler addition, as compared to those conventionally crosslinked with sulphur and accelerators $[5,6]$. The proportion of ionic crosslinks present in the form of multiplets or clusters in the elastomer network depends on the nature and structure of the elastomer macromolecule as well as the chemical nature and concentration of the carboxylic salt groups $[2,7]$. According to Eisenberg and King [8], clusters are formed by the association of multiplets. This association is caused by electrostatic interactions between multiplets and is impaired by the retractive elastic forces of the backbone chains. The restricted elastomer chain mobility in the proximity of ionic clusters results in the

*Corresponding author, e-mail: magdalena.przybyszewska@p.lodz.pl (C) BME-PT 
formation of a hard phase. The presence of a hard phase in ionic elastomers or ionomers has been confirmed by measurements of dynamic mechanical properties, demonstrating the occurrence of a biphasic transition in XNBR/zinc oxide composites $[9,10]$. Apart from the low glass transition temperature of elastomers, there is a high transition temperature due to the formation of a hard phase arising from the ionic clusters. Mandal et al. [5] confirmed the relationship between the high temperature transition and the presence of ionic aggregates in elastomer networks. Treatment of crosslinked samples with ammonia vapour caused the disappearance of the high temperature transition in the dynamic mechanical spectra. Ammonia acts as a plasticiser for the ionic aggregates, forming coordinating bonds with zinc ions of carboxylic salts or solvating the carboxylic ions. As a result, the ionic clusters are resolved, and the vulcanisate mechanical properties deteriorate.

Zinc oxide is a very effective and commonly used crosslinking agent for carboxylated elastomers $[5$, 10-13]. It can be used to produce vulcanisates with high tensile strength, tear resistance, hardness and hysteresis. The improved mechanical properties of ionic elastomers mainly result from their high ability for stress relaxation, due to elastomer chain slippage on the ionic cluster surface and reformation of ionic bonds upon external deformation of the sample. Moreover, ionic elastomers possess a thermoplastic character and can be processed in a molten state as a thermoplastic polymer [14]. However, there are some disadvantages to zinc-oxidecrosslinked carboxylic elastomers. The most important are the scorchiness, poor flex properties and high compression set [13]. In order to prevent scorchiness, carboxylated nitrile elastomers are crosslinked with zinc peroxide [2] or zinc peroxide/zinc oxide systems [13]. The vulcanisation of XNBR with zinc peroxide mainly leads to the formation of ionic crosslinks; covalent links are also formed between elastomer chains due to the peroxide action. However, higher vulcanisation times are required to achieve vulcanisates with a tensile strength and crosslink density comparable to that of vulcanisates crosslinked with zinc oxide [2]. In the case of XNBR vulcanisation with zinc peroxide/ zinc oxide systems, the curing is the sum of at least three processes: a very fast formation of ionic crosslinks due to the initial zinc oxide present, per- oxide crosslinking that leads to the formation of covalent links (peroxide action) and ionic crosslinking due to the production of zinc oxide from peroxide decomposition. The last process, which decays with vulcanisation time, is most likely related to the formation of ionic species [13]. The achieved vulcanisation times are considerably higher, as compared to those of XNBR crosslinking with zinc oxide. Therefore, apart from the scorch problems, zinc oxide is still commonly used as a crosslinking agent of carboxylated nitrile rubbers.

Taking into account the fact that, during the crosslinking process, zinc oxide reacts with carboxylic groups of elastomer, which leads to the formation of carboxylic salts (ionic crosslinks), the most important parameters influencing zinc oxide activity are its specific surface area, particle size and morphology. These parameters determine the size of the interphase between the crosslinking agent and elastomer chains.

The influence of zinc oxide particle size on the curing of carboxylated rubbers was reported by Hamed and Hua [15]. However, there are still some important aspects, which should be clarified. The effect of zinc oxide particle morphology on the crosslinking process and vulcanisate properties has not yet been reported.

In this work, we applied zinc oxides with different specific surface areas, particle sizes and morphologies (spheres, whiskers, snowflakes) as crosslinking agents of carboxylated nitrile elastomer, in order to determine the relationship between zinc oxide characteristics and activity in the crosslinking process.

\section{Experimental section}

\subsection{Materials}

Carboxylated nitrile elastomer XNBR (Krynac X7.50) containing $27 \mathrm{wt} \%$ acrylonitrile and 6.7 wt\% carboxylic groups was obtained from Bayer C.O. The Mooney viscosity was (ML1+4 $\left(100^{\circ} \mathrm{C}\right)$ :47). Zinc oxides with different specific surface areas, particle sizes and morphologies were applied as crosslinking agents. Didodecyldimethylammonium bromide (DDAB, Fluka) was used to improve the dispersion of the zinc oxide particles in the elastomer matrix.

The physical characteristics of the zinc oxides applied are given in Table 1 . 
Table 1. Characteristics of zinc oxides

\begin{tabular}{|l|c|l|l|}
\hline Symbol & Specific surface area $\left[\mathbf{m}^{2} / \mathbf{g}\right]$ & Particle morphology & \multicolumn{1}{c|}{ Producer } \\
\hline $\mathrm{ZnO} 10$ & 10.00 & spheres and rods & Sigma-Aldrich \\
\hline $\mathrm{ZnO} 15$ & $15-25$ & whiskers & Sigma-Aldrich \\
\hline $\mathrm{ZnO} \mathrm{24}$ & 24.43 & snowflakes & Institute of High Pressure Physics, Polish Academy of Science \\
\hline $\mathrm{ZnO} \mathrm{40}$ & 40.86 & spheres & Institute of High Pressure Physics, Polish Academy of Science \\
\hline $\mathrm{ZnO} \mathrm{42}$ & 42.50 & spheres & Qinetiq Nanomaterials Limited \\
\hline ZnO 50 & 50.00 & spheres & Nanostructured \& Amorphous Materials, Inc. \\
\hline
\end{tabular}

\subsection{Zinc oxide specific surface area}

The specific surface area of zinc oxide was measured using low-temperature nitrogen adsorption (78 K) method with Sorptomatic 1900 (Fisons Instruments) apparatus. The specific surface area was determined with BET method based on the first section of nitrogen adsorption isotherm for $P / P_{0}=0.05-0.35$. Before the measurement zinc oxide was vacuum out-gassed in the temperature $373 \mathrm{~K}$ for $24 \mathrm{~h}$.

\subsection{Zinc oxide aggregate size}

The size of the zinc oxide aggregates was determined using a Zetasizer Nano Series S90 (Malvern Instruments) apparatus. The size of the zinc oxide particles in water suspensions was measured based on the DLS (Dynamic Light Scattering) method. The concentration of the suspensions was $0.05 \mathrm{~g} / \mathrm{l}$.

\subsection{Preparation and characterisation of rubber compounds}

Rubber compounds with the formulation given in Table 2 were prepared using a laboratory two-roll mill. The samples were cured at $160^{\circ} \mathrm{C}$ until they developed a $90 \%$ increase in torque, measured by an oscillating disc rheometer.

The crosslink density $\left(v_{T}\right)$ of the vulcanisates was determined by equilibrium swelling in toluene, based on the Flory-Rehner equation [16]. The Huggins parameter of the elastomer-solvent interaction $\chi$ was calculated from Equation (1) [12]:

$\chi=0.487+0.228 V_{r}$

Table 2. Composition of the XNBR-based rubber compounds [phr]

\begin{tabular}{|l|r|r|r|r|}
\hline XNBR & 100 & 100 & 100 & 100 \\
\hline ZnO & 3 & 5 & 6 & 8 \\
\hline DDAB & 1 & 1 & 1 & 1 \\
\hline
\end{tabular}

where $V_{r}$ is the volume fraction of elastomer in the swollen gel. In order to determine the content of ionic crosslinks in the elastomer network, samples were swollen in toluene in a dessicator with saturated ammonia vapour (25\% aqueous solution). The content of ionic crosslinks $(\Delta v)$ was calculated from Equation (2):

$$
\Delta v=\frac{v_{T}-v_{A}}{v_{T}} \cdot 100 \%
$$

where $v_{A}$ is the crosslink density determined for samples treated with ammonia vapour using the Huggins elastomer-solvent interaction parameter described by Equation (3) [17]:

$\chi=0.483+0.320 V_{r}$

The tensile properties of the vulcanisates were determined according to ISO-37, with a ZWICK 1435 universal machine.

\subsection{Dynamic-mechanical analysis}

Dynamic-mechanical measurements were carried out in the tension mode using a DMTA V viscoanalyser (Rheometric Scientific). Measurements of the dynamic moduli were performed over the temperature range $\left(-100-150^{\circ} \mathrm{C}\right)$ with a heating rate of $2^{\circ} \mathrm{C} / \mathrm{min}$, at a frequency of $1 \mathrm{~Hz}$ and a strain amplitude of $0.02 \%$. The temperature of the elastomer glass transition was determined based on the maximum of $\tan \delta=f(T)$, where $\tan \delta$ is the loss factor and $T$ is the measurement temperature.

\subsection{Shrinkability measurements}

In order to measure the shrinkability of the XNBR vulcanisates, the samples were stretched at ambient temperature until reaching an elongation of $300 \%$ at the time $48 \mathrm{~h}$; they were then stabilised in the stretched form at $\left(-7^{\circ} \mathrm{C}\right)$ for $8 \mathrm{~h}$. Finally, the stretched samples were allowed to shrink at $70^{\circ} \mathrm{C}$ 
for $48 \mathrm{~h}$. The lengthwise shrinkage was calculated according to Equation (4) [18]:

$$
S_{h}[\%]=\frac{L_{s t r}-L_{s h r}}{L_{s t r}} \cdot 100
$$

where $S_{h}$ is the percentage of shrinkability, $L_{s t r}$ is the length of the sample after stretching, and $L_{s h}$ is the length of the shrunk sample.

\subsection{Scanning Electron Microscopy (SEM)}

The morphology of the zinc oxide particles and their dispersion in the elastomer matrix were estimated using Scanning Electron Microscopy with a LEO 1530 SEM microscope. The XNBR vulcanisates were broken down in liquid nitrogen, and the fracture surfaces of the vulcanisate were examined. Prior to the measurements, the samples were coated with carbon.

\section{Results and discussion}

\subsection{Zinc oxide particle size and morphology}

The particle size of zinc oxide is a main parameter that has a great influence on the $\mathrm{ZnO}$ activity. A reduction in particle size results in an increase in the zinc oxide specific surface area, providing better contact between the crosslinking agent particles and the elastomer chains. Moreover, the morphology of the $\mathrm{ZnO}$ particles determines the size of the interphase between zinc oxide and the elastomer. The sizes of the zinc oxide aggregates are presented in Table 3. Figure 1 shows the distribution of particle sizes as a function of particle number.

The morphologies of the zinc oxide particles or aggregates are presented in Figure 2a-2f.

Agglomerates of microsized zinc oxide (Figure 2a) used commercially in XNBR crosslinking consisted of primary particles with a wide size distribution from several hundreds of nanometres to several micrometres. The $\mathrm{ZnO} 10$ particles revealed

Table 3. Zinc oxide aggregate size

\begin{tabular}{|c|c|c|c|}
\hline Zinc oxide & $\begin{array}{c}\text { Aggregate size } \\
{[\mathbf{n m}]}\end{array}$ & $\begin{array}{c}\text { Size of the aggregate } \\
\text { main fraction [nm] }\end{array}$ & $\begin{array}{c}\text { Number } \\
{[\%]}\end{array}$ \\
\hline $\mathrm{ZnO} 10$ & $1886-2671$ & 2118 & 46 \\
\hline $\mathrm{ZnO} 15$ & $185-664$ & 371 & 26 \\
\hline $\mathrm{ZnO} 24$ & $147-262$ & 185 & 35 \\
\hline $\mathrm{ZnO} 40$ & $92-131$ & 116 & 38 \\
\hline $\mathrm{ZnO} 42$ & $185-295$ & 234 & 36 \\
\hline $\mathrm{ZnO} 50$ & $130-208$ & 165 & 36 \\
\hline
\end{tabular}

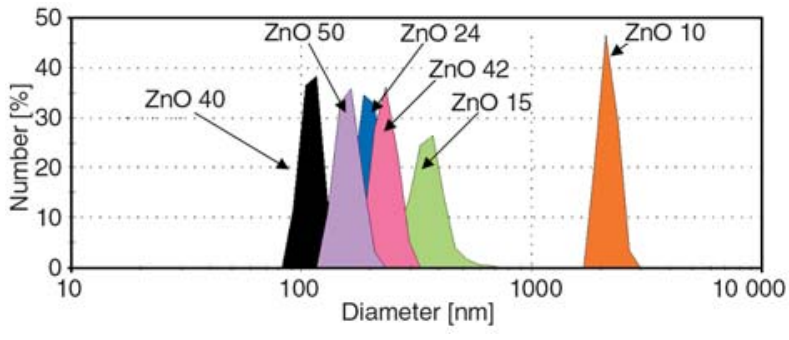

Figure 1. Zinc oxide particle size distribution by number

a variety of morphologies and irregular shapes (deformed spherical particles, elongated rods and blocks with sharp edges). The microsized $\mathrm{ZnO}$ agglomerates were broken down upon ultrasonic treatment. The aggregate size distribution determined in water dispersion ranged from 1.9-2.7 $\mu \mathrm{m}$, with the main aggregate fraction at $2.1 \mu \mathrm{m}(46 \%)$.

The $\mathrm{ZnO} 15$ particles were elongated whiskers with a length of $100-300 \mathrm{~nm}$ and a diameter below $100 \mathrm{~nm}$ (Figure 2b). The aggregate size, as determined in water, was within the range of 185-664 nm, with the size of the main number fraction being $371 \mathrm{~nm}(26 \%)$. However, in the case of elongated particles, the orientation of the whiskers in the field of laser radiation influenced the obtained data. Therefore, it could be supposed that the measured particle size was a combination of whisker diameter and length.

Interesting morphological structures were observed in the case of $\mathrm{ZnO} 24$ (Figure 2c). Zinc oxide aggregates revealed a shape of snowflakes or threedimensional flowers consisting of several wires and plates growing from a single core. The primary particles with a size of about $200 \mathrm{~nm}$ formed microsized aggregates. In water dispersion, the size of the zinc oxide aggregates was reduced upon ultrasonic treatment to $185 \mathrm{~nm} \mathrm{(35 \% )} \mathrm{(Table} \mathrm{3).}$

Zinc oxides with specific surface areas of 40.86 , 42.5 and $50 \mathrm{~m}^{2} / \mathrm{g}$ were found to be spherical with a size of about $100 \mathrm{~nm}$, which agglomerated, forming clusters $10-20 \mu \mathrm{m}$ in size (Figure 2d-2f). Upon ultrasonic treatment, the $\mathrm{ZnO}$ agglomerates were reduced in the water dispersion to aggregates with sizes ranging from $92-131 \mathrm{~nm}(\mathrm{ZnO} 40), 185-$ $295 \mathrm{~nm}$ (ZnO 42) and 130-208 nm (ZnO 50) (Table 3).

Elastomers have a hydrophobic nature; therefore, the size of the zinc oxide particles was measured in a liquid hydrophobic medium-paraffin oil, which was chosen as the model for an elastomer matrix (Table 4). The aim of this study was to estimate the 


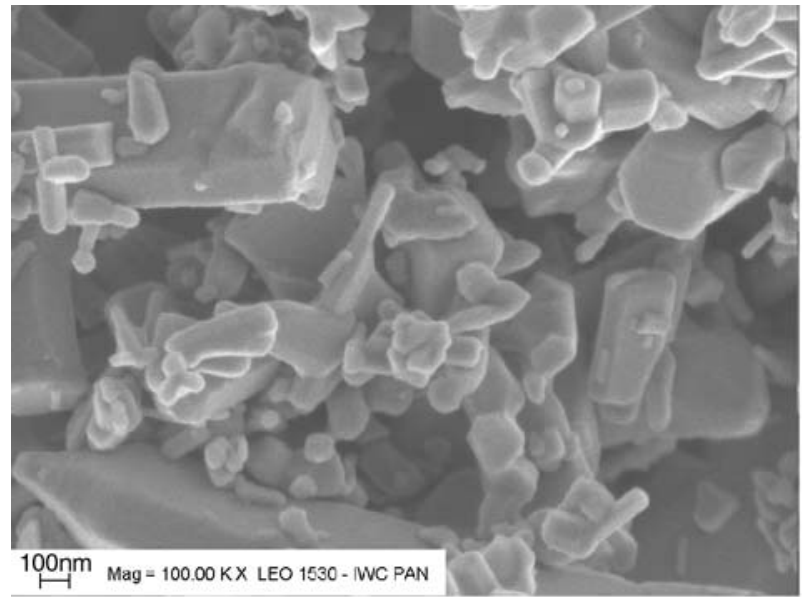

a)

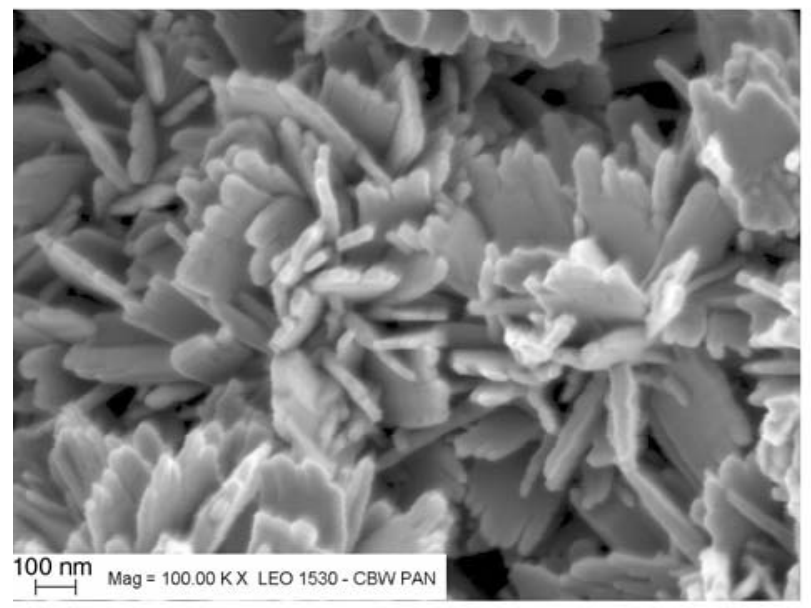

c)

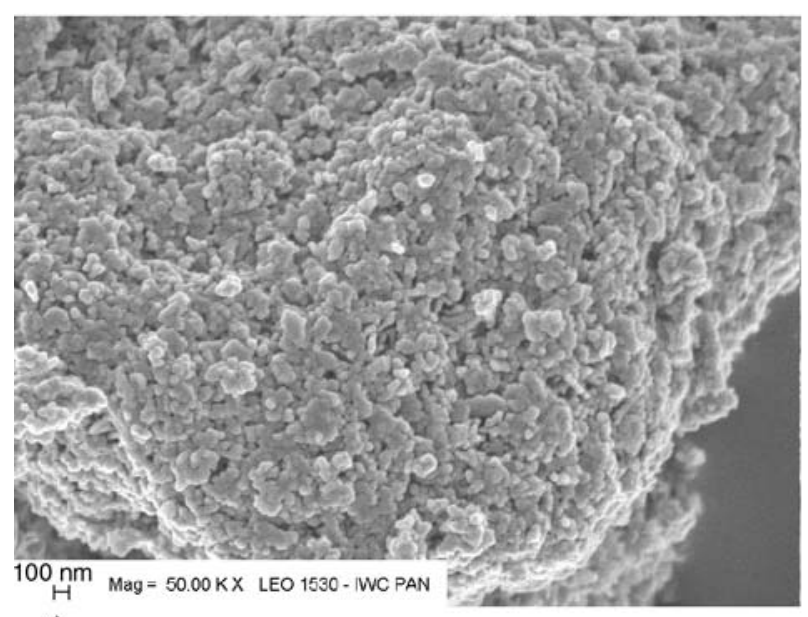

e)

Figure 2. SEM images of zinc oxides: a) $\mathrm{ZnO} \mathrm{10,} \mathrm{b)} \mathrm{ZnO} 15$, c) $\mathrm{ZnO} 24$, d) $\mathrm{ZnO}$ 40, e) $\mathrm{ZnO} 42$, f) $\mathrm{ZnO} 50$

Table 4. Zinc oxide agglomerate size in paraffin oil

\begin{tabular}{|c|c|}
\hline Zinc oxide & Agglomerate size $[\boldsymbol{\mu m}]$ \\
\hline $\mathrm{ZnO} 10$ & 10.0 \\
\hline $\mathrm{ZnO} 15$ & 7.9 \\
\hline $\mathrm{ZnO} 24$ & 7.9 \\
\hline $\mathrm{ZnO} 40$ & 1.3 \\
\hline $\mathrm{ZnO} 42$ & 9.3 \\
\hline $\mathrm{ZnO} 50$ & 5.4 \\
\hline
\end{tabular}
( $\mathrm{ZnO} 40)$ to $10 \mu \mathrm{m}(\mathrm{ZnO} 10)$.

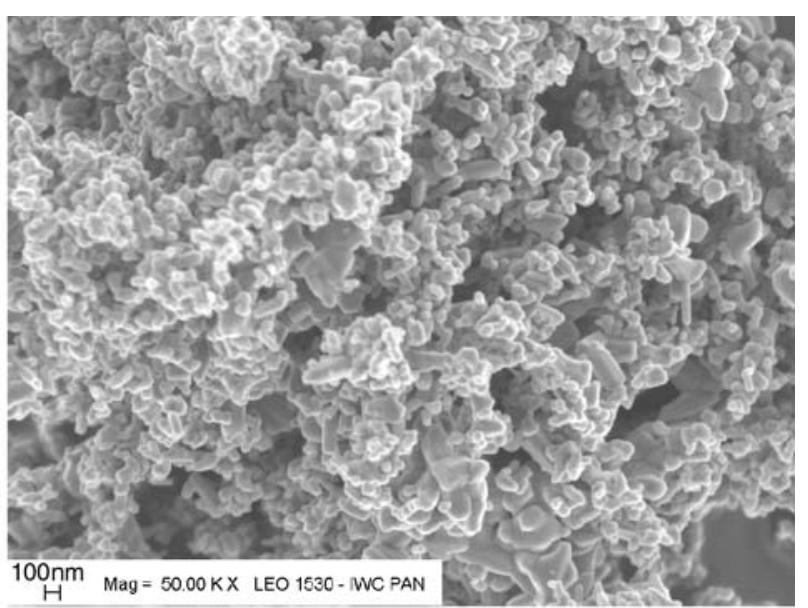

b)

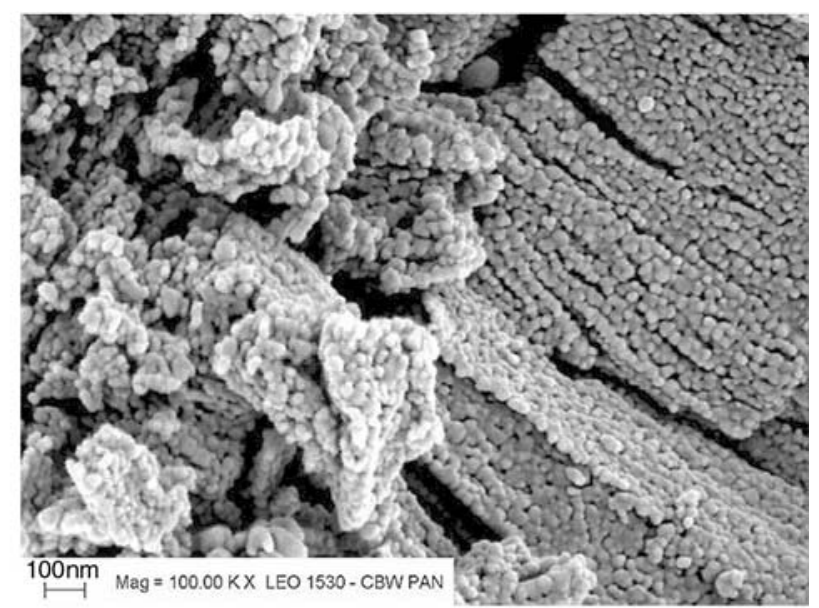

d)

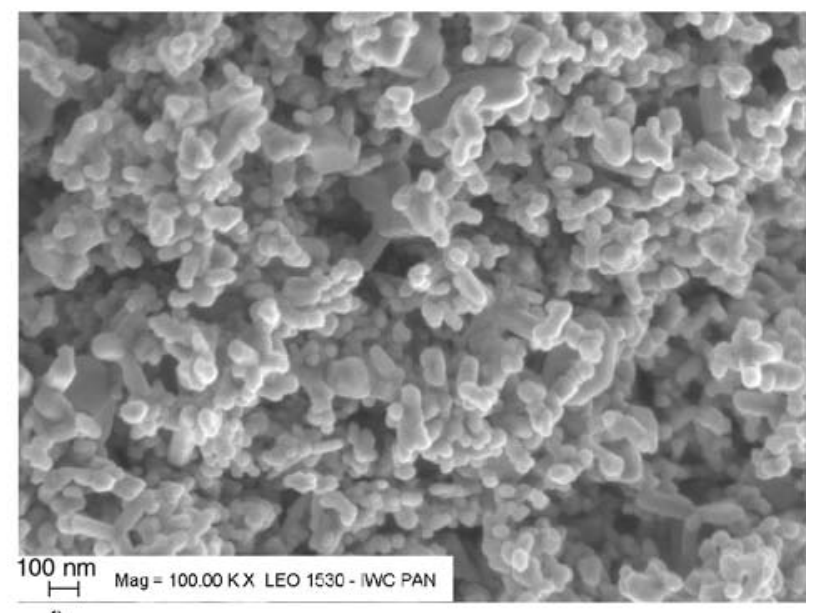

f)

tendency of zinc oxide particles to agglomerate in elastomer. Unfortunately, zinc oxide particles exhibited a high ability for aggregation or agglomeration in paraffin oil. Primary particles formed microsized clusters with sizes ranging from $1.3 \mu \mathrm{m}$ 


\subsection{Dispersion of zinc oxide particles in elastomer matrix}

Assuming that zinc oxide particles diffuse through the elastomer matrix and react with carboxylic groups of elastomer chains, forming ionic crosslinks, the dispersion of $\mathrm{ZnO}$ particles in elastomer has a great importance as far as the activity of zinc oxides and their influence on vulcanisate

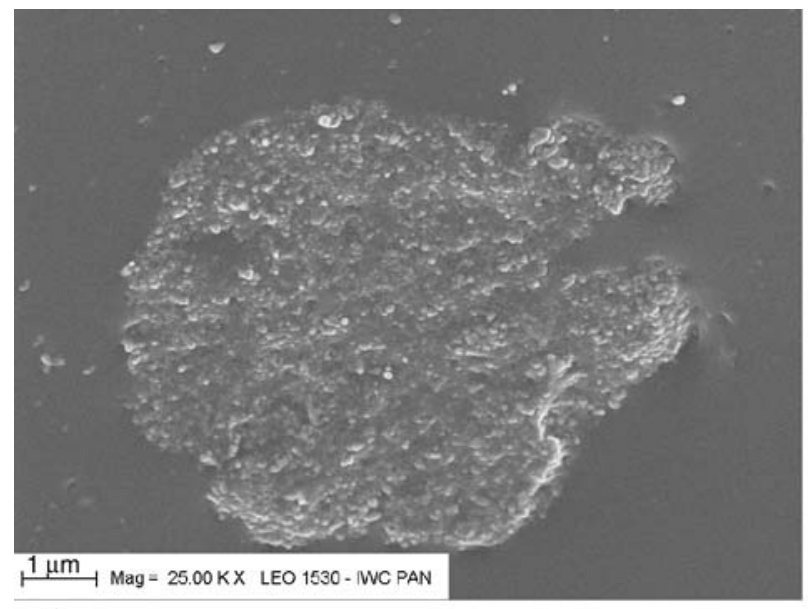

a)

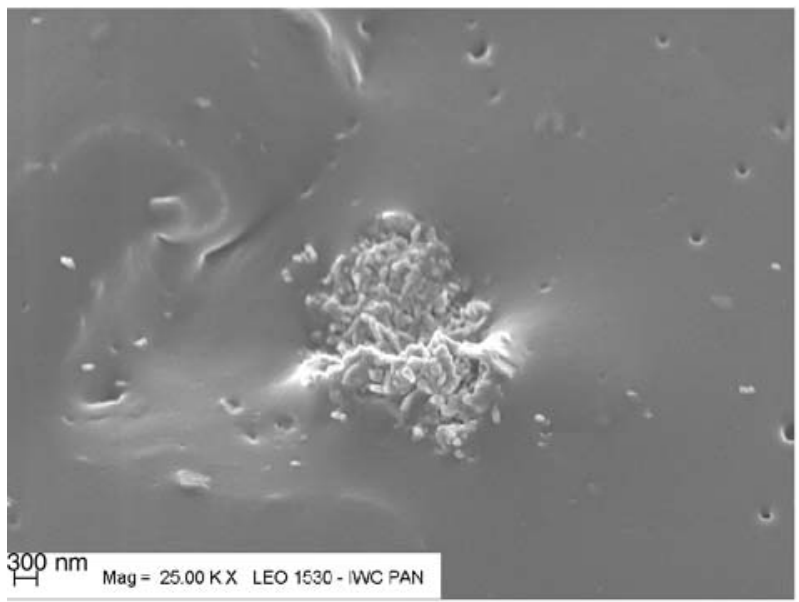

c)

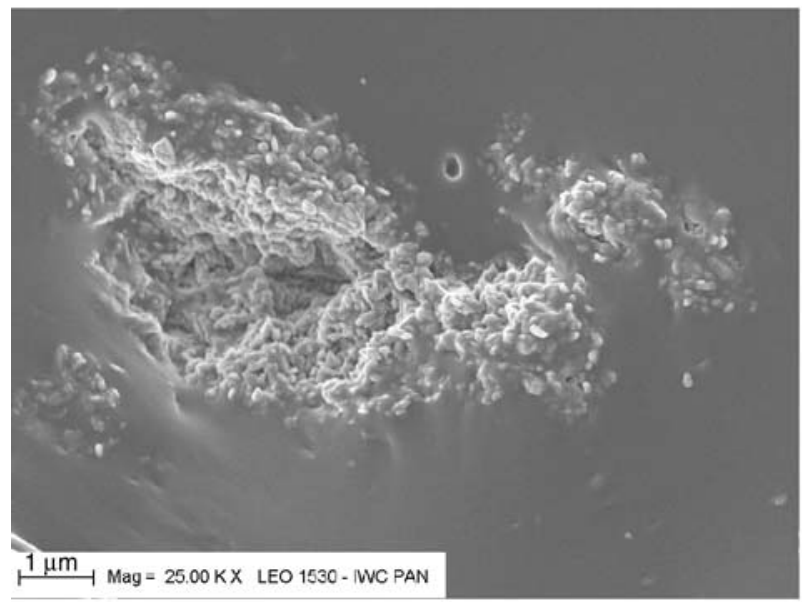

e) properties are concerned. The dispersion of nanoparticles in the elastomer was estimated based on the SEM images of vulcanisate surfaces (Figure $3 \mathrm{a}-3 \mathrm{f})$.

The zinc oxide particles were poorly dispersed in the elastomer matrix and, therefore, were not homogeneously distributed (Figure 3a). They created microsized agglomerates with complex structures.

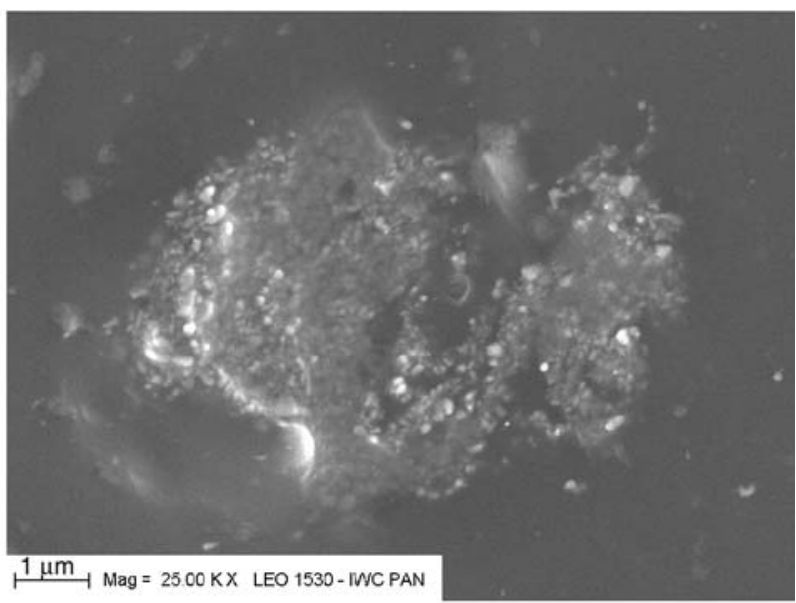

b)

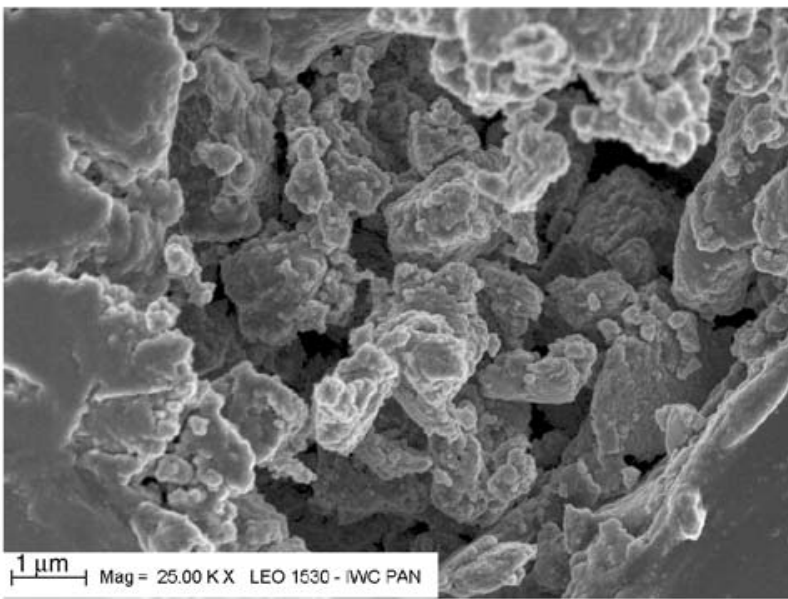

d)

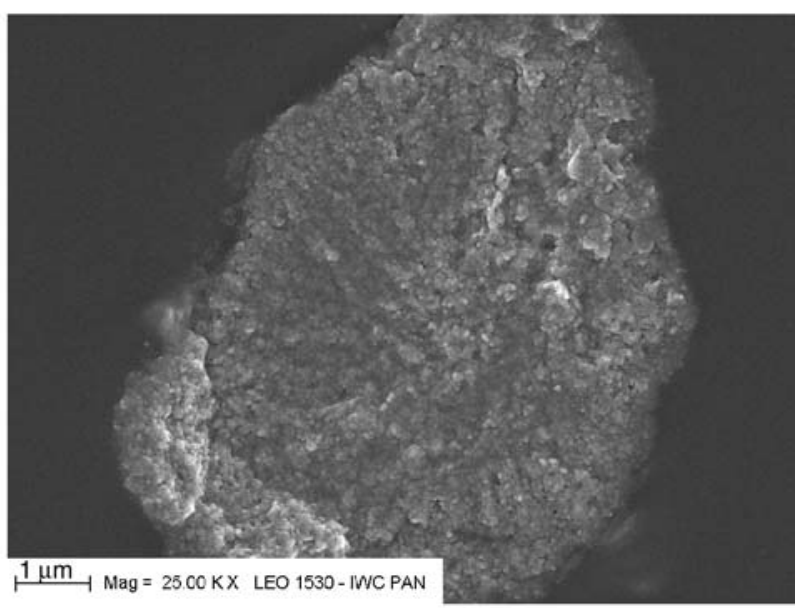

f)

Figure 3. SEM images of XNBR vulcanisates with: a) $\mathrm{ZnO} \mathrm{10,} \mathrm{b)} \mathrm{ZnO} 15$, c) $\mathrm{ZnO} 24$, d) $\mathrm{ZnO} 40$, e) $\mathrm{ZnO} 42$, f) $\mathrm{ZnO} 50$ 
The whisker particles of $\mathrm{ZnO} 15$ (Figure $3 \mathrm{~b}$ ) created agglomerates several micrometres in size, which were surrounded by an elastomer film and were tightly bound to the elastomer matrix. It could be supposed that the wetting of $\mathrm{ZnO} 15$ clusters with elastomer resulted in the good mechanical properties of the XNBR vulcanisates, despite the poor dispersion of the whiskers.

The $\mathrm{ZnO} 24$ snowflake particles exhibited the weakest tendency to agglomerate. They created clusters about $3 \mu \mathrm{m}$ in size (Figure $3 \mathrm{c}$ ). The optimal dispersion of $\mathrm{ZnO} 24$ in elastomer should lead to its high activity in the crosslinking process.

The spherical zinc oxide particles ( $\mathrm{ZnO} 40, \mathrm{ZnO} 42$ and $\mathrm{ZnO} 50$ ) were distributed very heterogeneously in the carboxylated nitrile rubber. The primary nanoparticles formed microsized agglomerates with irregular shapes, which displayed poor adhesion to the elastomer (Figure 3d-3f). Specifically, hollow structures were created by the $\mathrm{ZnO} 40$ nanoparticles (Figure 3d). The strong tendency of $\mathrm{ZnO}$ nanoparticles to agglomerate arises from their high surface energy. The differences in the dispersed states of $\mathrm{ZnO} 40, \mathrm{ZnO} 42$ and $\mathrm{ZnO} 50$ spherical nanoparticles in the elastomer resulted from different dispersive components of their surface energy and ability to undergo specific interactions. The influence of these parameters on the compatibility between zinc oxide particles and elastomer was thoroughly discussed [19]. The presence of impurities on $\mathrm{ZnO} 40$ surface is probably the reason for its poor interfacial interaction with rubber. $\mathrm{ZnO} 40$ was achieved by calcination of zinc oxalate, which was precipitated from hydrous solution of ammonium oxalate. Therefore, it contains some residues of hydroxyl groups, that remained after reaction. Moreover, the lowest content of crystalline phase (88\%) compared to other zinc oxides (95-98\%) as well as the presence of defects (oxygen vacancies) in the crystalline structure of $\mathrm{ZnO} 40$ affect its activity towards XNBR elastomer.

\subsection{Mechanical properties and crosslink density of vulcanisates}

The influence of zinc oxide particle size and morphology on the activity in crosslinking of carboxylated nitrile elastomer was estimated based on the tensile properties and crosslink density of the vul-

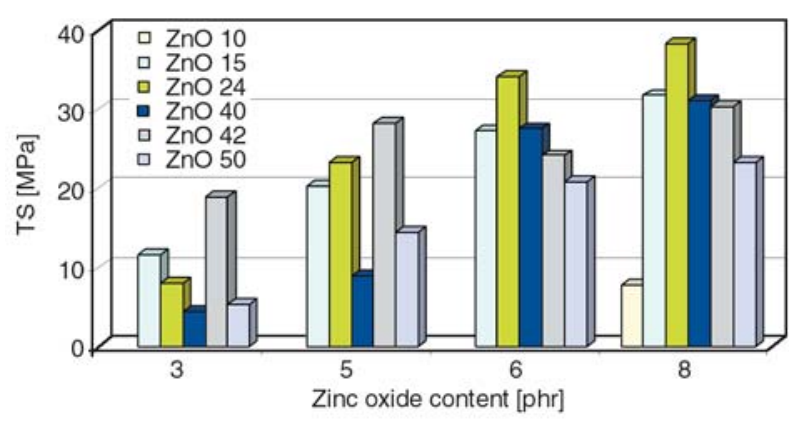

Figure 4. Tensile strength of XNBR vulcanisates

canisates. The results are given in Table 5 and Figure 4.

From the data presented in Figure 4, it follows that the application of zinc oxide nanoparticles considerably increased the tensile strength of the vulcanisates, as compared to those produced using conventional microsized $\mathrm{ZnO} 10$. The tensile strength of the vulcanisates increased with the amount of zinc oxide in the composite. Moreover, the stress at a relative elongation of $300 \%$ increased, and the elongation at break decreased, due to an increase in the vulcanisate crosslink density (Table 5). The increment in vulcanisate tensile strength with the amount of zinc oxide arises from the increase in ionic crosslink content in the elastomer network $(\Delta v)$. The presence of strong and multifunctional labile ionic clusters, which are able to move on the surface of the solid zinc oxide particles, resulted in the high ability of vulcanisates for stress relaxation, and as a consequence, an improvement in mechanical strength was achieved. Moreover, the considerable chain slippage and reformation of bonds in the elastomer network upon external stress contributed to the increase in vulcanisate tensile strength.

It could be supposed that the activity of zinc oxides in the crosslinking process will rise with the specific surface area. The presented results prove that the morphology of zinc oxide particles affects the vulcanisate crosslink density and mechanical properties more strongly than the specific surface area. The highest tensile strength (about $40 \mathrm{MPa}$ ) was achieved with a vulcanisate containing zinc oxide with three-dimensional snowflake particles ( $\mathrm{ZnO} 24)$ (Figure 4). Moreover, the highest crosslink density and ionic crosslink content in the elastomer network (70\%) were achieved for vulcanisates crosslinked with $\mathrm{ZnO} 24$. Most likely, the high activity of this zinc oxide arises from a better contact between the surface of the crosslinking 
Table 5. Mechanical properties and crosslink density of XNBR vulcanisates

\begin{tabular}{|c|c|c|c|c|c|}
\hline Zinc oxide & $\mathrm{ZnO}$ content [phr] & SE300 [MPa] & EB [\%] & $v_{T} \cdot 10^{6}\left[\mathrm{~mol} / \mathrm{cm}^{3}\right]$ & $\Delta v[\%]$ \\
\hline ZnO 10 (microsized) & 8 & 3.6 & 426 & 24.1 & 29 \\
\hline \multirow{4}{*}{$\begin{array}{l}\mathrm{ZnO} 15 \\
\text { (whisker particles) }\end{array}$} & 3 & 1.8 & 802 & 12.2 & 29 \\
\hline & 5 & 2.4 & 740 & 14.1 & 27 \\
\hline & 6 & 2.9 & 717 & 15.2 & 24 \\
\hline & 8 & 3.2 & 709 & 20.9 & 42 \\
\hline \multirow{4}{*}{$\begin{array}{l}\mathrm{ZnO} 24 \\
\text { (snowflake particles) }\end{array}$} & 3 & 1.6 & 871 & 27.0 & 45 \\
\hline & 5 & 3.2 & 652 & 48.3 & 63 \\
\hline & 6 & 4.8 & 617 & 62.9 & 70 \\
\hline & 8 & 7.0 & 586 & 64.6 & 68 \\
\hline \multirow{4}{*}{$\begin{array}{l}\mathrm{ZnO} 40 \\
\text { (spherical particles) }\end{array}$} & 3 & 1.6 & 705 & 8.9 & 28 \\
\hline & 5 & 2.5 & 554 & 23.5 & 15 \\
\hline & 6 & 3.3 & 580 & 29.1 & 17 \\
\hline & 8 & 3.3 & 582 & 31.0 & 19 \\
\hline \multirow{4}{*}{$\begin{array}{l}\mathrm{ZnO} 42 \\
\text { (spherical particles) }\end{array}$} & 3 & 2.5 & 579 & 17.1 & 16 \\
\hline & 5 & 4.1 & 518 & 19.2 & 13 \\
\hline & 6 & 4.8 & 576 & 23.6 & 11 \\
\hline & 8 & 5.3 & 514 & 28.7 & 21 \\
\hline \multirow{4}{*}{$\begin{array}{l}\mathrm{ZnO} 50 \\
\text { (spherical particles) }\end{array}$} & 3 & 1.2 & 861 & 20.0 & 49 \\
\hline & 5 & 2.1 & 682 & 28.1 & 54 \\
\hline & 6 & 2.9 & 620 & 30.6 & 67 \\
\hline & 8 & 3.0 & 631 & 37.0 & 64 \\
\hline
\end{tabular}

SE300 - stress at 300\% relative elongation; TS - tensile strength; EB - elongation at break; $v_{\mathrm{T}}$ - vulcanisate crosslink density; $\Delta v-$ content of ionic crosslinks in elastomer network

agent particles and the elastomer chains (especially elastomer carboxylic groups), as compared to other zinc oxides. The specific shape and complex structure of $\mathrm{ZnO} 24$ aggregates cause an increase in the size of the interphase between the elastomer and the snowflake particles, as compared to the spheres. Moreover, $\mathrm{ZnO} 24$ nanoparticles exhibited the best dispersion in the elastomer matrix, which also contributed to the higher tensile strength and crosslink density in these vulcanisates, especially containing the high amount of $\mathrm{ZnO}$ (6; 8 phr). High tensile strength was also observed for the vulcanisates containing zinc oxide with whisker particles ( $\mathrm{ZnO} 15)$.

Among the zinc oxides with spherical particles, the highest tensile strength was observed for vulcanisates with $\mathrm{ZnO} 42$, especially with the small amount of zinc oxide $(3 ; 5 \mathrm{phr})$. The weaker activity of the other zinc oxides was probably due to the poor dispersion of the particles in the elastomer matrix. Large and expanded agglomerates could act as critical sites, which may generate microcracks and initiate breaking of the sample under external stress. Moreover, the agglomeration of zinc oxide particles caused the surface area to decrease, followed by a decrease in the size of the interphase between the zinc oxide and the rubber chains. $\mathrm{ZnO} 40$ was observed to be less efficient as a crosslinking agent of carboxylated nitrile rubber, mainly due to the presence of hollow, large agglomerates with poor adhesion to the elastomer. Weak dispersion of $\mathrm{ZnO} 50$ nanoparticles (Figure $3 \mathrm{e}$ ) was also a reason for deterioration of vulcanisates tensile strength, despite the high content of ionic crosslinks.

It should be noticed that not only the size and morphology of $\mathrm{ZnO}$ nanoparticles or their tendency for agglomeration affect zinc oxide activity in elastomer crosslinking. The surface properties of $\mathrm{ZnO}$ and its ability to specific interactions, which were reported in our previous work [19], must be taken into account. Considering the zinc oxide acceptordonor properties and the ability to undergo specific interactions, it was concluded that $\mathrm{ZnO} 15$ and $\mathrm{ZnO} 24$, which had strong interactions with donor solvents as well as $\mathrm{ZnO} 50$, which strongly interacted with acetonitrile, are most prone to interactions with elastomers containing donor functional groups (e.g. nitrile groups $-\mathrm{C} \equiv \mathrm{N}$ ). From physicochemical point of view, these oxides reveal the highest activity towards carboxylated acrylonitrilebutadiene elastomer. As a consequence, vulcanisates with high content of ionic crosslinks were achieved.

In previous work, we proved that it is possible to reduce the amount of zinc ions in acrylonitrile- 
butadiene rubber [20]. It should be noted that the application of zinc oxide nanoparticles allowed the amount of $\mathrm{ZnO}$ to be reduced in XNBR compounds, without a detrimental effect on the vulcanisate properties. The highest reduction in the zinc oxide amount is possible in the case of $\mathrm{ZnO} 42$, since the vulcanisates crosslinked with $3 \mathrm{phr}$ of this oxide exhibited a tensile strength twice as great as that of vulcanisates produced with microsized zinc oxide, which is used commercially in crosslinking process. This is very important from an ecological point of view, because the European Union requires that the amount of zinc oxide be reduced as much as possible.

\subsection{Dynamic-mechanical properties of vulcanisates}

A dynamic-mechanical analysis was performed to confirm the existence of ionic clusters in the elastomer network. The loss factor $\tan \delta$, as a function of temperature, for the vulcanisates with microsized zinc oxide $\mathrm{ZnO} 10$ and with zinc oxide $\mathrm{ZnO} 42$ with spherical nanoparticles is presented as an example in Figure 5. The values of glass transition temperature $T_{g}$ are given in Table 6.

The existence of two transitions can be observed. The first transition is the glass transition of the elastomer at low temperatures, with a maximum that represents $T_{g}$. The determined glass transition temperature for the vulcanisate with $\mathrm{ZnO} 10$ was

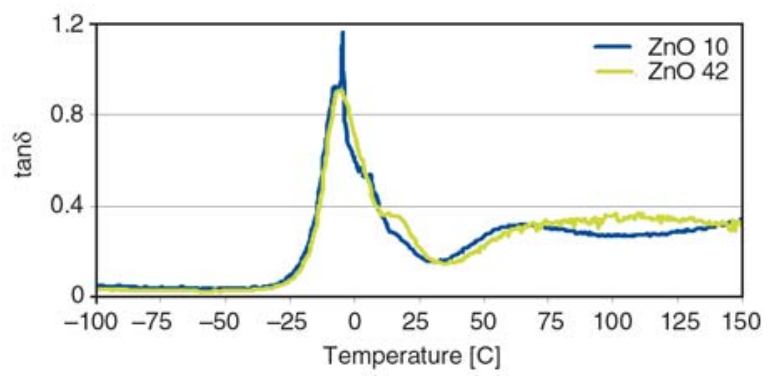

Figure 5. Tan $\delta$ versus temperature for XNBR vulcanisates containing zinc oxide

Table 6. Glass transition temperature of XNBR vulcanisates

\begin{tabular}{|c|c|}
\hline Vulcanisate & $\mathbf{T}_{\mathbf{g}}\left[{ }^{\circ} \mathbf{C}\right]$ \\
\hline XNBR/ZnO 10 & -4.5 \\
\hline XNBR/ZnO 15 & -5.1 \\
\hline XNBR/ZnO 24 & -4.9 \\
\hline XNBR/ZnO 40 & -5.5 \\
\hline XNBR/ZnO 42 & -5.3 \\
\hline XNBR/ZnO 50 & -5.1 \\
\hline
\end{tabular}

$\left(-4.5^{\circ} \mathrm{C}\right)$, whereas for vulcanisates with zinc oxide nanoparticles $\mathrm{Tg}$ values were within the range from $\left(-4.9^{\circ} \mathrm{C}\right)$ to $\left(-5.5^{\circ} \mathrm{C}\right)$. Therefore, it can be concluded that the zinc oxide particle size and morphology did not affect the elastomer $T_{g}$ value considerably. The presence of additional maxima in the tan $\delta$ plot at the temperatures $6^{\circ} \mathrm{C}(\mathrm{ZnO} 10)$ and $17^{\circ} \mathrm{C}(\mathrm{ZnO} 42)$ was probably due to the existence of differently immobilised elastomer phases on the $\mathrm{ZnO}$ particle surfaces.

The second transition is the ionic transition, occurring at high temperatures $\left(50-100^{\circ} \mathrm{C}\right)$, resulting from the occurrence of a hard phase arising from ionic associations-ionic clusters or aggregates. Similar transitions were observed for all XNBR vulcanizates. This confirms the existence of a biphasic structure in the XNBR-ZnO system.

In the case of the vulcanisate containing $\mathrm{ZnO} 42$, the considerable decrease in the tan $\delta$ versus temperature maximum resulted from higher interactions between $\mathrm{ZnO} 42$ and the elastomer, which prevented the rubber chains from a free relaxation at the glass transition temperature.

\subsection{Shrinkability of XNBR vulcanisates}

Heat-shrinkable polymers are widely used in packaging and in the cable industry; therefore, the shrinkability of XNBR vulcanisates crosslinked with zinc oxide is very important from a technological point of view. According to Mishra et al. [18], the shrinkage of polymer occurs due to an internal rearrangement of the structural elements within the stretched sample. The shrinkage driving force originates from oriented polymer chains of crystalline and amorphous phase. In the case of polyolefin/ elastomer blends, the crosslinked elastomeric phase causes an enhancement in the blend shrinkability upon heating. It is believed that crosslinked points in the elastomer network serve as memory points, enhancing the heat shrinkability [21].

The examined samples were stretched above the glass transition temperature $T_{g}$ until reaching an elongation of $300 \%$; they were then stabilised in the stretched form at $\left(-7^{\circ} \mathrm{C}\right)$ and shrunk above the ionic transition temperature at $70^{\circ} \mathrm{C}$. The heat shrinkability values of the XNBR samples containing $8 \mathrm{phr}$ of zinc oxide are presented in Table 7.

Vulcanisates of carboxylated nitrile elastomer crosslinked with zinc oxides exhibited heat shrink- 
Table 7. Shrinkability of XNBR vulcanisates

\begin{tabular}{|c|c|c|c|}
\hline Vulcanisate & $\mathbf{L}_{\text {str }}[\mathbf{c m}]$ & $\mathbf{L}_{\text {shr }}[\mathbf{c m}]$ & $\mathbf{S}_{\mathbf{h}}[\mathbf{\%}]$ \\
\hline XNBR/ZnO 10 & 11.2 & 3.9 & 65 \\
\hline XNBR/ZnO 15 & 11.2 & 3.5 & 69 \\
\hline XNBR/ZnO 24 & 11.2 & 2.7 & 76 \\
\hline XNBR/ZnO 40 & 11.2 & 3.5 & 69 \\
\hline XNBR/ZnO 42 & 11.2 & 2.7 & 76 \\
\hline XNBR/ZnO 50 & 11.2 & 2.6 & 77 \\
\hline
\end{tabular}

ability. The highest shrinkage upon heating (76 and $77 \%$ ) was achieved for vulcanisates containing $\mathrm{ZnO} 24$ snowflake nanoparticles and spherical particles of $\mathrm{ZnO} 42$ and $\mathrm{ZnO} 50$. The lower shrinkability of the vulcanisates with the other zinc oxides ( $\mathrm{ZnO} 10, \mathrm{ZnO} 15$ and $\mathrm{ZnO} 40$ ) resulted from a lower crosslink density and ionic crosslink content in the elastomer network. Since the crosslinked points in the elastomer network serve as shape memory sites, a higher crosslink density improves the shrinkability of the vulcanisate. The stretched XNBR samples were shrunk upon heating above the temperature of the ionic transition, due to the occurrence of ionic multiplets in the elastomer network, which are multifunctional and labile crosslinks. Therefore, it can be concluded that the decomposition or rearrangement of the ionic clusters is one of the causes of heat shrinkability in XNBR vulcanisates containing zinc oxide.

\section{Conclusions}

Zinc oxides with different particle sizes and morphologies were used as crosslinking agents of carboxylated nitrile elastomer.

We conclude that the application of zinc oxide nanoparticles allowed for the realisation of vulcanisates with considerably better mechanical properties and higher crosslink density, as compared to vulcanisates crosslinked with microsized zinc oxide, which is used commercially as a crosslinking agent. Vulcanisates containing the same amount of zinc oxide nanoparticles exhibited a tensile strength about four times greater than that of vulcanisates with microsized particles. Moreover, $3 \mathrm{phr}$ of nanosized $\mathrm{ZnO} 15, \mathrm{ZnO} 24$ or $\mathrm{ZnO} 42$ is sufficient to obtain composites with comparable or even better tensile strengths, as compared to vulcanisates containing $8 \mathrm{phr}$ of industrially used microsized $\mathrm{ZnO}$. Therefore, the application of nanosized zinc oxide allows the amount of zinc oxide to be reduced by almost $40 \%$. This is a very important ecological goal, since zinc oxide is classified as toxic to aquatic species, and the European Union requires that the amount of zinc oxide in rubber compounds be reduced. Moreover, it should be noted that vulcanisates of carboxylated nitrile elastomer crosslinked with zinc oxide reveal heat shrinkability.

The morphology of zinc oxide particles mainly affects the activity in the crosslinking process. Particle size or zinc oxide specific surface area does not seem to have a considerable influence on the crosslinking agent efficiency. The highest activity was observed for zinc oxide with a specific surface area of $24.43 \mathrm{~m}^{2} / \mathrm{g}$ and three-dimensional snowflake particles ( $\mathrm{ZnO} 24)$. The specific shape and complex structure of $\mathrm{ZnO} 24$ aggregates, consisting of wires or plates growing from a single core, provide an increase in the size of the interphase between the elastomer carboxylic groups and the snowflake particles. As a result, vulcanisates with higher crosslink density and ionic crosslink content are achieved. These vulcanisates exhibit the best mechanical properties (TS about $40 \mathrm{MPa}$ ), mainly due to the high content of ionic clusters, which are multifunctional and labile crosslinks and can rearrange upon external stress, leading to stress relaxation. Moreover, $\mathrm{ZnO} 24$ nanoparticles have the lowest ability for agglomeration in the elastomer matrix and create the smallest agglomerates, which concentrate the stresses during sample deformation to a smaller degree, as compared to the large agglomerates formed by other zinc oxides.

\section{Acknowledgements}

The authors wish to acknowledge the Polish Ministry of Science and Higher Education for supporting this research.

\section{References}

[1] Ibarra L., Rodriguez A., Mora I.: Ionic nanocomposites based on XNBR-OMg filled with layered nanoclays. European Polymer Journal, 43, 753-761 (2007).

DOI: $\underline{10.1016 / j . e u r p o l y m j .2006 .12 .007}$

[2] Ibarra L., Alzorriz M.: Vulcanization of carboxylated nitrile rubber (XNBR) by zinc peroxide. Polymer International, 48, 580-586 (1999). DOI: $10.1002 /($ SICI) 1097-0126(199907)48:7<580:: AID-PI186>3.0.CO;2-4 
[3] Dunn J. R.: Carboxylated rubber. in 'Handbook of Elastomers' (eds.: Bowmick A. K., Stephens H. L.) Marcel Dekker, New York, 561-590 (2001).

[4] Eisenberg A.: Clustering of ions in organic polymers. A theoretical approach. Macromolecules, 3, 147-154 (1970). DOI: $\underline{10.1021 / \mathrm{ma60014a006}}$

[5] Mandal U. K., Tripathy D. K., De S. K.: Dynamic mechanical spectroscopic studies on plasticization of an ionic elastomer based on carboxylated nitrile rubber by ammonia. Polymer, 37, 5739-5742 (1996). DOI: $\underline{10.1016 / \mathrm{S} 0032-3861(96) 00545-9}$

[6] Przybyszewska M., Zaborski M.: Nanoparticle zinc oxide applied for crosslinking of butadiene rubbers. in ' 8 th European Symposium on Polymer Blends and Eurofillers. Bruges, Belgium’ 116 (2005).

[7] MacKnight W. J.: Available ionomers. in 'Structure and properties of ionomers' (eds.: Pireni M., Eisenberg A.) NATO ASI Series C Mathematical and Physical Sciences, Vol. 198, 1-10 (1986).

[8] Eisenberg A., King M.: Ion containing polymers. Academic Press, New York (1997).

[9] Mandal U. K., Tripathy D. K., De S. K.: Effect of silica filler on dynamic mechanical properties of ionic elastomer based on carboxylated nitrile rubber. Journal of Applied Polymer Science, 55, 1185-1191 (2003). DOI: $\underline{10.1002 / a p p .1995 .070550805}$

[10] Mandal U. K., Tripathy D. K., De S. K.: Effect of carbon black fillers on dynamic mechanical properties of ionic elastomer based on carboxylated nitrile rubber. Plastics, Rubber and Composites Processing and Application, 24, 19-25 (1995).

[11] Fritzsche J., Das A., Jurk R., Stöckelhuber K. W., Heinrich G., Klüppel M.: Relaxation dynamics of carboxylated nitrile rubber filled with organomodified nanoclay. Express Polymer Letters, 2, 373-381 (2008). DOI: $10.3144 /$ expresspolymlett.2008.44

[12] Zaborski M., Kosmalska A.: Silica modified by use of organosilanes as a filler for carboxylated butadieneacrylonitrile rubber. Kautschuk Gummi Kunststoffe, 58, 354-357 (2005)
[13] Ibarra L., Marcos-Fernandez A., Alzorriz M.: Mechanistic approach to the curing of carboxylated nitrile rubber (XNBR) by zinc peroxide/zinc oxide. Polymer, 43, 1649-1655 (2002).

DOI: $10.1016 /$ S0032-3861(01)00734-0

[14] Chatterjee K., Naskar K.: Development of thermoplastic elastomers based on maleated ethylene propylene rubber (m-EPM) and polypropylene (PP) by dynamic vulcanization. Express Polymer Letters, 1, 527-534 (2007).

DOI: $10.3144 /$ expresspolymlett.2007.75

[15] Hamed G. R., Hua K-C.: Effect of ZnO particle size on the curing of carboxylated NBR and carboxylated SBR. Rubber Chemistry and Technology, 77, 214 226 (2004).

[16] Flory P. J., Rehner J.: Statistical mechanics of crosslinked polymer networks. II. Swelling. Journal of Chemical Physics, 11, 521-526 (1943). DOI: $10.1063 / 1.1723792$

[17] Przepiórkowska A., Chrońska K., Zaborski M.: Chrome-tanned leather shavings as a filler of butadiene-acrylonitrile rubber. Journal of Hazardous Materials, 141, 252-257 (2007). DOI: 10.1016/j.jhazmat.2006.06.136

[18] Mishra J. K., Raychowdhury S., Das C. K.: Effect of interchain crosslinking on the shrinkability of the blends consisting of grafted low-density polyethylene and carboxylated nitrile rubber. Materials Letters, 46, 212-218 (2000). DOI: $10.1016 / \mathrm{S} 0167-577 \mathrm{X}(00) 00172-5$

[19] Przybyszewska M., Krzywania A., Zaborski M., Szynkowska M. I.: Surface properties of zinc oxide nanoparticles studied by inverse gas chromatography. Journal of Chromatography A, 1216, 5284-5291 (2009).

DOI: 10.1016/j.chroma.2009.04.094

[20] Przybyszewska M., Zaborski M., Jakubowski B., Zawadiak J.: Zinc chelates as new activators for sulphur vulcanization of acrylonitrile-butadiene elastomer. Express Polymer Letters, 3, 256-266 (2009). DOI: 10.3144 /expresspolymlett.2009.32

[21] Patra P. K., Das C. K.: Blends of polyolefins and chlorosulphonated polyethylene (CSM) with special reference to their shrinkability and flame retardancy. International Journal of Polymeric Materials, 35, 103 118 (1997). DOI: $10.1080 / 00914039708039757$ 